\title{
Difference in clinical crown length of maxillary central incisors and gingival display at rest and during smiling based on gender
}

\author{
Nadia Atina Zaini*, Rasmi Rikmasari*, Lisda Damayanti* \\ *Department of Prosthodontics, Faculty of Dentistry, Universitas Padjadjaran
}

\begin{abstract}
Introduction: The aim of the present study was to investigate the effect of gender on the degree of maxillary central incisors and associated gingival display when the lips are at rest and during smiling. Methods: A total of 65 subjects (40 females [61.5\%]; 25 males [38.5\%]) of Malaysian Malay community studied in UNPAD were included in the study. All of the subjects had all natural anterior teeth present with no caries, extreme occlusal wear, restorations, extrusion, obvious deformities, or tooth mobility. The visible portions of the maxillary central incisor, and associated gingival at rest and smiling were measured vertically from the lower border of the upper lip to the incisal edge of the incisors. The measurements were measured using an electronic digital caliper and repeated three times. The mean value was calculated and statistical analyses were performed by Student $t$ test. Results: Outcome of the study indicated that there is marked difference statistically $(p<0.05)$ with the clinical crown length display at rest (CCLR). However, the clinical crown length display during smiling (CCLS) and gingival display during smiling (GD) differences is non significant $(p>0.05)$ between these two genders. Conclussion: Females displayed more clinical crown length of maxillary central incisors than males at rest. During smiling, no gender differences in maxillary central incisors display were recorded, however, females displayed more maxillary gingival than males.
\end{abstract}

Keywords: clinical crown length, gingival display, gender

\section{INTRODUCTION}

In recent years, esthetic aspects have gained attention in reconstructive dentistry and hence, the discussion of the position of restoration margin has reemerged. Driven by increased interest within dentistry and greater patient awareness outside the profession, facial esthetics and the desire of patients to improve their appearance have grown in importance..$^{1,2}$ The desire for an attractive smile and improved esthetics often motivate persons in modern society to seek dental treatment. ${ }^{3,4}$ In social interaction, our attention appears mainly directed towards the mouth and eyes of the face of the person speaking. ${ }^{5}$ As the mouth is the centre of communication in the face, the esthetic appearance of the oral region during smiling is a conspicuous part of facial attractiveness. The aesthetic or display. ${ }^{6,7}$ zone is composed of the size, shape, position and color of the displayed teeth, the gingival contour, the buccal corridor and the framing of the lips. The range of the 
esthetic zone is defined by the movements of the upper and lower lip during smiling and speech. ${ }^{8}$

Facial expressions and the smile are the key components for nonverbal communication. The smile has an important role in determination of the first impression of a person. ${ }^{9}$ Interest in the overall facial appearance has increased in contemporary prosthodontic treatment.9,10,11 rather than concentrating on one aspect such as smile analysis.

The presence of maxillary anterior teeth plays an important role in facial aesthetics. Any prosthodontic treatment, removable or fixed, that involves their replacement is considered to be rather critical. The amount of visible anterior teeth, with lip at rest or during function, is an important esthetic factor in determining the outcome of fixed and removable prosthodontic care, implant dentistry, operative dentistry, anterior esthetic procedures and orthognathic surgery. ${ }^{12}$

The extent of tooth display at rest and during smiling is mainly determined by the upper and lower lip positions and their movements during function. ${ }^{7}$ In some studies, female subjects have been shown to display significantly more gingival tissue than males.,13,14 suggested a gummy smiler males and has been reported as a female characteristic.

The amount of visible portions of anterior teeth is determined by muscle positions that vary from person to another. It provides an excellent starting point for vertical positioning anterior teeth that can be modified as necessary in any clinical situation..$^{12}$ The findings of this study should help the dentist in providing aesthetic prosthodontic treatment that involves replacement of anterior teeth.

Increased esthetic demands in fixed and removable prosthetic restorations have focused mainly on the maxillary anterior teeth at rest. ${ }^{12}$ and during smiling. ${ }^{15}$ Thus, it is of clinical interest to investigate the degree of tooth display in the maxillary anterior region at rest and smiling as sufficient data are lacking at present. The identification of any possible correlations between tooth and gingival display, gender, and age is of interest as they could be used as guidelines for esthetic considerations in prosthetic restorations of teeth. This research was done to investigate the degree of visibility of clinical crown length of maxillary central incisor surfaces when the lip at rest and smiling, to know whether there is a differentiation between males and females on their maxillary central incisor and gingival display at rest and during smiling and to determine the smile line of Malaysian Malay community.

\section{METHODS}

This research took a descriptive and analytical survey approach of the Malaysian Malay student community batch 2007 and 2008 studying in Universitas Padjadjaran, Bandung.

The total number of Malaysian Malay student batch 2007 and 2008 studying in Universitas Padjadjaran is 165 . The total number of male is 57 , while the total number of female is 108 . The survey was done through a stratified random proportional sampling technique of Malaysian Malay student community studying in Universitas Padjadjaran and fulfills all the following population criteria pure Malay at least 2 generation above, age between 18-28 years old, undergraduate students of Universitas Padjadjaran, class 2007 and 2008, Angle's normal Class 1 molar relationship mirror, physically healthy with normal growth and development pattern, all anterior teeth of the maxilla and mandible had fully erupted and available without caries, extreme occlusal wear, restorations, extrusion, obvious deformities, or tooth mobility, all the anterior teeth of the maxilla and mandible do not have any visible abnormalities disease, or other pathologic condition, subjects had not undergone orthodontic or surgical treatment (i.e., gingival surgery or extraction of teeth), subjects with a history of congenital anomalies, lip trauma, or facial surgery were excluded, those who are prepared to participate in this study and have signed the informed consent.

This minimal sample was based upon the opinion of Gay and Diehl (1992) in an independent sample using t-test. In order for this research to unbiased, the number of sample of the males and females are taken proportionally making 25 males and 40 females in proportion to the ratio of Malaysian Malay males and females studying in Universitas Padjadjaran that fulfill the criteria. 


\section{RESULTS}

The data of the clinical crown length of maxillary central incisor that shown at rest and smiling of 65 (25 males and 40 females) Malaysian Malay student in Universitas Padjadjaran of ages between 18 to 28 years old were collected and recorded in the examination forms. The data obtained from samples were tabulated into the tables drawn in Appendix 7 and Appendix 8.

The results of statistical calculations that show the mean, standard deviation and mean difference between two genders as a whole can be viewed on Table 1 and Picture 2. Picture 3 . and 4 . showed the difference of gingival display between two genders. The results of the data after analyzing are tabulated into Table 2, Table 3, Table 4, Table 5, Table 6, Table 7 and Table 8 as below.

The Picture 4 shows the frequency of

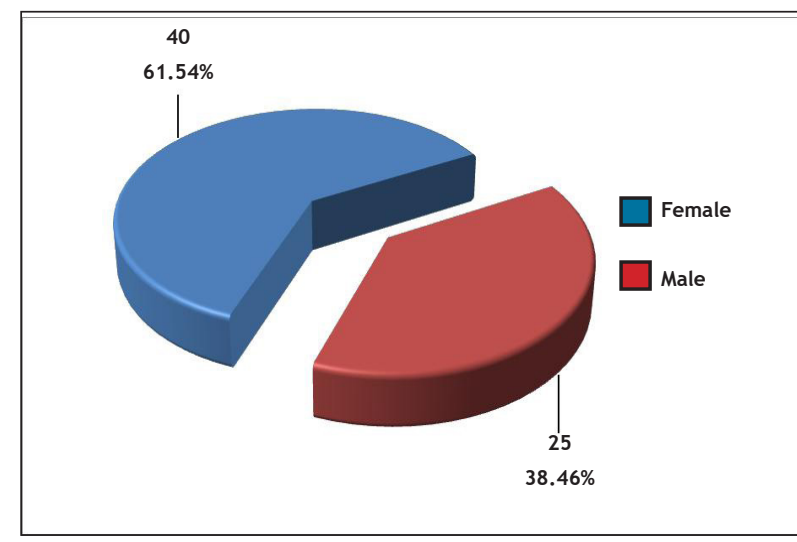

Picture 1. Distribution of the Research Sample Frequency According to Gender

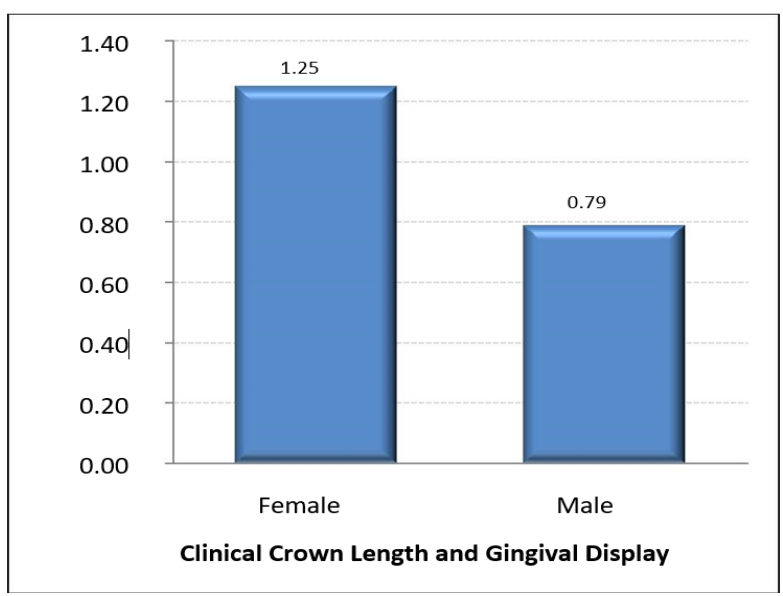

Picture 3. The mean of gingival display between male and female the male and female sample distribution. The distribution of the sample is rather uneven due to ratio of the gender itself which have more females than males. In a pilot study that was conducted earlier, has found that out of 33 people $(20 \%$ of the whole population), 26 of them fulfill all the criteria needed. The number of males and females taken is proportionate to the ratio of males and females that is 11 males and 22 females.

9 males out of the 11 males fulfilled the criteria while 17 out of 22 females fulfilled the criteria. Thus the sample size of this research on which it is carried out is 65 people with 40 females and 25 males in it.

The values of male clinical crown length and female clinical crown length of maxillary central incisor were of normal distribution and homogenous. Using the data obtained, the mean length of male and female clinical crown length of undergraduate Malaysian Malay students, aged
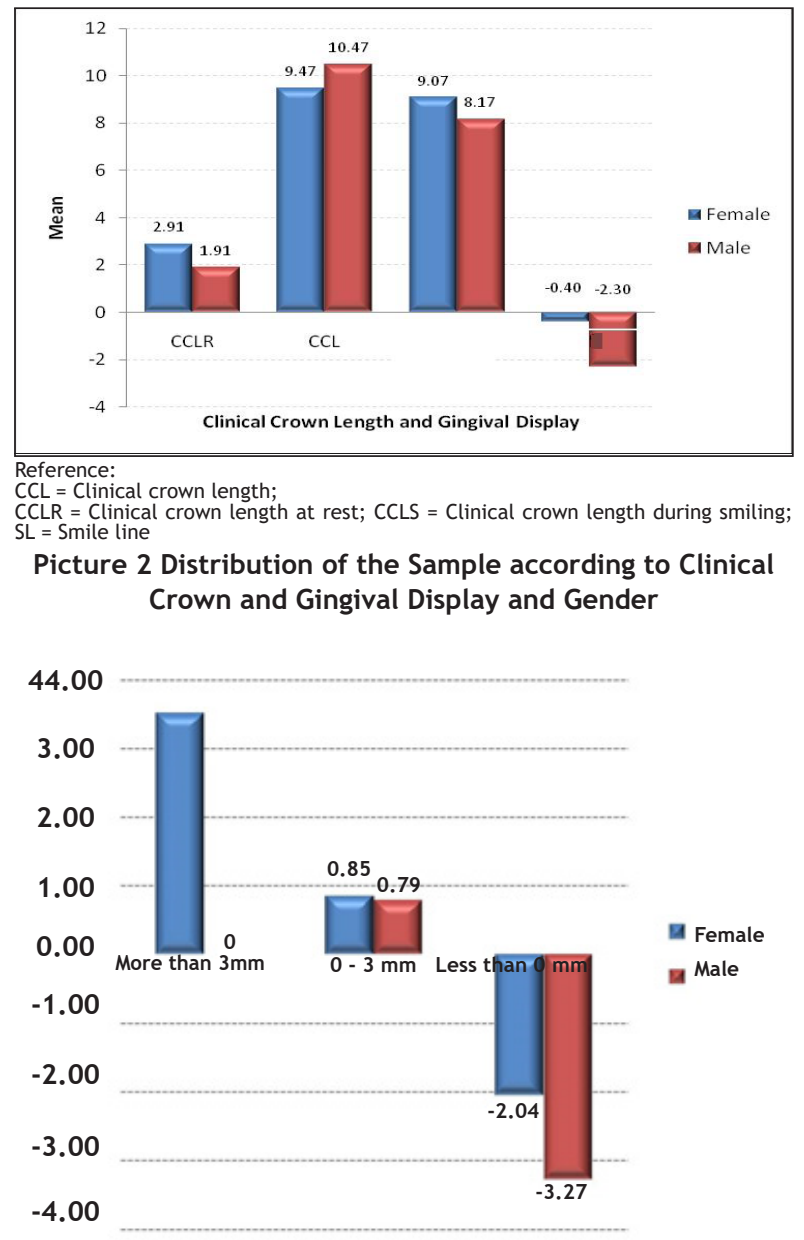

Picture 4. Level of gingival display during smiling according to gender 
Padjadjaran Journal of Dentistry 2013;25(1):48-56.

Table 1. Distribution of the sample frequency according to Clinical Crown and Gingival Display and Gender

\begin{tabular}{|c|c|c|c|c|c|}
\hline Clinical Crown and Gingival Display & Gender & $N$ & Mean & $\begin{array}{c}\text { Std. } \\
\text { Deviation }\end{array}$ & $\begin{array}{l}\text { Mean } \\
\text { Difference }\end{array}$ \\
\hline \multirow[t]{2}{*}{$\mathrm{CCL}$} & Female & 40 & 9,47 & 0,824 & 1,00 \\
\hline & Male & 25 & 10,47 & 1,193 & \\
\hline \multirow[t]{2}{*}{ CCLR } & Female & 40 & 2,91 & 1,266 & 1,00 \\
\hline & Male & 25 & 1,91 & 0,922 & \\
\hline \multirow[t]{2}{*}{ CCLS } & Female & 40 & 9,07 & 2,137 & 0,90 \\
\hline & Male & 25 & 8,17 & 2,253 & \\
\hline \multirow[t]{2}{*}{ SL } & Female & 40 & $-0,40$ & 2,209 & 1,90 \\
\hline & Male & 25 & $-2,30$ & 2,957 & \\
\hline
\end{tabular}

Reference $\mathrm{CCL}=$ Clinical crown length; $\mathrm{CCLR}=$ Clinical crown length at rest; $\mathrm{CCLS}=$ Clinical crown length during smiling; $\mathrm{SL}=$ Smile line (mean of both positive and negative values)

Table 2. Distribution of the Sample Displaying Gingival during Smiling

\begin{tabular}{cccccccc}
\hline Gingival Display during Smiling & Gender & $\mathbf{N}$ & $\mathrm{n}$ & $\%$ & Mean & Std. Deviation & Mean Difference \\
\hline \multirow{2}{*}{ GD } & Female & 40 & 20 & 50.0 & 1,25 & 1,145 & \multirow{2}{*}{0,47} \\
\cline { 2 - 7 } & Male & 25 & 6 & 24.0 & 0,79 & 0,271 & \\
\hline
\end{tabular}

Table 3. The Level of Gingival Display during Smiling According to Gender

\begin{tabular}{cccccc}
\hline Category & Gender & Mean & Std. Dev. & Freq. & Percentage \\
\hline More than $3 \mathrm{~mm}$ & Female & 3,507 & 0,219 & 3 & $4,62 \%$ \\
& Male & - & - & - & - \\
$0-3 \mathrm{~mm}$ & Female & 0,853 & 0,655 & 17 & $26,15 \%$ \\
& Male & 0,786 & 0,271 & 6 & $9,23 \%$ \\
Less than $0 \mathrm{~mm}$ & Female & $-2,045$ & 1,729 & 20 & $30,77 \%$ \\
& Male & $-3,270$ & 2,733 & 19 & $29,23 \%$ \\
\hline
\end{tabular}

Table 4. Results of Homogenous Varians and Independent T-Test Samples

\begin{tabular}{ccccc}
\hline Levene's Test for Equality of Variances & & Mean & Independent-Samples & T-Test \\
\hline Homogenity & p-value & Difference & t & p-value \\
\hline $\begin{array}{c}\text { Equal variances } \\
\text { assumed } \\
\begin{array}{c}\text { Equal variances not } \\
\text { assumed }\end{array}\end{array}$ & 0,184 & 1,00 & $-3,991^{*}$ & 0,000 \\
& & & & 0,001 \\
\hline
\end{tabular}

*) Significant at level alpha $5 \%$

18 to 28 from the class of 2007 and 2008 in UNPAD were derived.

With reference to table 4.1 , the mean clinical crown length of Malaysian Malay males and females are $10.47 \pm 1.19 \mathrm{~mm}$ and $9.47 \pm 0.82 \mathrm{~mm}$ respectively. Thus the mean clinical crown length of maxillary central incisor of males is greater compared to females. Reference: $\mathrm{CCL}=$ Clinical crown length; $C C L R=$ Clinical crown length at rest; $C C L S=$ Clinical crown length during smiling; $S L=$ Smile line Picture 2 Distribution of the Sample according to Clinical Crown and Gingival Display and Gender The values of male CCLR and female CCLR were of normal distribution and homogenous.

Using the data obtained, the mean length of male CCLR and the length of female CCLR of undergraduate Malaysian Malay students in Universitas Padjadjaran, aged 18-28 from the class of 2007 and 2008 in UNPAD were derived. With reference to table 4.1 , it can be noted that the mean length of male CCLR was $1.91 \pm 0.92 \mathrm{~mm}$, whereas the mean length of female CCLR was $2.91 \pm 1.26 \mathrm{~mm}$ respectively. Thus the mean clinical crown length of maxillary central incisor display at rest of females is greater compared to males. Table 4.2 Distribution of the Sample Displaying The values of male smile line and female smile line were of normal distribution and homogenous. Using the data obtained, the mean of male and female smile line of undergraduate Malaysian Malay students, aged 18 to 28 from the class of 2007 and 2008 in UNPAD were derived. 


\begin{tabular}{|c|c|c|c|c|}
\hline \multirow{2}{*}{\multicolumn{2}{|c|}{$\begin{array}{l}\text { Levene's Test for } \\
\text { Equality of Variances }\end{array}$}} & \multirow{3}{*}{$\begin{array}{c}\text { Mean } \\
\text { Difference }\end{array}$} & \multicolumn{2}{|c|}{ Independent-Samples } \\
\hline & & & & T-Test \\
\hline Homogenity & $\mathrm{p}$-value & & $\mathrm{t}$ & $\mathrm{p}$-value \\
\hline Equal variances & & & $2,957^{*}$ & 0,004 \\
\hline assumed & 0,274 & 1,90 & & \\
\hline $\begin{array}{c}\text { Equal variances no } \\
\text { assumed }\end{array}$ & & & $2,766^{*}$ & 0,008 \\
\hline
\end{tabular}

Table 7. Results of Homogenous Varians and Independent T-Test Samples

\begin{tabular}{|c|c|c|c|c|}
\hline \multirow{2}{*}{\multicolumn{2}{|c|}{$\begin{array}{l}\text { Levene's Test for } \\
\text { Equality of Variances }\end{array}$}} & \multirow{3}{*}{$\begin{array}{c}\text { Mean } \\
\text { Difference }\end{array}$} & \multicolumn{2}{|c|}{ Independent-Samples } \\
\hline & & & & T-Test \\
\hline Homogenity & p-value & & $\mathrm{t}$ & $\mathrm{p}$-value \\
\hline Equal variances & & & 0,974 & 0,340 \\
\hline assumed & 0,019 & 0,47 & & \\
\hline $\begin{array}{c}\text { Equal variances } \\
\text { not assumed }\end{array}$ & & & 1,668 & 0,108 \\
\hline
\end{tabular}

*) Significant at level alpha 5\%

With reference to table 4.1, the mean smile line of Malaysian Malay males and females are $-2.30 \pm 2.95$ $\mathrm{mm}$ and $-0.40 \pm 2.20 \mathrm{~mm}$ respectively. Thus the mean smile line of females is greater compared to males. The values of male gingival display and female gingival display during smiling were of normal distribution and homogenous. Using the data obtained, the mean of male and female gingival display during smiling of undergraduate Malaysian Malay students, aged 18 to 28 from the class of 2007 and 2008 in UNPAD were derived.

With reference to table 4.3 , the mean of gingival display during smiling for Malaysian Malay males and females are $0.79 \pm 0.27 \mathrm{~mm}$ and $1.25 \pm 1.15$ $\mathrm{mm}$ respectively. Thus the mean gingival display of females during smiling is greater compared to males.

\section{DISCUSSION}

In the present clinical study, the clinical crown length of maxillary central incisors and it associated gingival display was evaluated. The results are compared between male and female subjects of the same age group and same race. Overall, there are three hypotheses in total to be tested. The mean length of the clinical crown length of maxillary central incisor for both males and females in this study are $10.47 \pm 1.19 \mathrm{~mm}$ and
$9.47 \pm 0.82 \mathrm{~mm}$ respectively. After subjecting the data to statistical analysis, the results showed that there is a statistically significant difference between the mean length of male and female clinical crown length. This finding is consistent with the findings of Sterrett 1999. in which he stated that all width and length of maxillary anterior teeth measures were significantly greater for males than for females.

The results of his study toward the Caucasian group are $10.19 \mathrm{~mm}$ for males and $9.39 \mathrm{~mm}$ for females. Other researcher such as also got the same conclusion that mean value for maxillary central incisor length for females were less than for males with $10.73 \pm 2.02 \mathrm{~mm}$ for males and $10.47 \pm 2.34 \mathrm{~mm}$ for females. This difference could be attributed to the differences in physical structures of both sexes. ${ }^{16}$ Besides that, a short crown sometimes can be due to attrition or excessive gingival encroachment. ${ }^{17}$

The common feature of the smile characteristics in the present study was the fact that females presented with higher smile lines than males. Overall, after the mean calculation is done, it is stated that the mean for smile line in females is $-0.40 \mathrm{~mm}$ while $-2.30 \mathrm{~mm}$ for males. The negative values indicate that the smile line or the position of the upper lip during smiling for this sample is all below the gingival line with 
female have $0.40 \mathrm{~mm}$ below the gingival line and male have $2.30 \mathrm{~mm}$ below the gingival line. This result is consistent with Jensen et al study in the year of 1999. He stated that the smile line is all higher in female subject compare to male for all ethnic groups, and was most pronounced in the Asian population, where females (up to 35 years) with high smile lines comprised almost $50 \%$ of the population. Similar findings of higher smile lines for females have been described in Californian Caucasian. ${ }^{9}$ and in New England Caucasian. ${ }^{13}$ subjects. In Jorgen's study who's the subjects is $\mathrm{fr}$ founds a significant decrease in the extent of the smile line was evident in the older (more than 36 years) male populations. The high proportion of high smile lines in the young female Asian population may be explained on the basis of the cranial facial structures with bimaxillary protrusions frequently encountered in these subpopulations. ${ }^{18}$

The results from this study revealed the mean clinical crown length of maxillary central incisor at rest is higher in female than male. The mean length of male is $1.91 \pm 0.92$ $\mathrm{mm}$, whereas the mean length of female is $2.91 \pm 1.26 \mathrm{~mm}$ respectively. When subjected to hypothesis testing, the results showed that there is a significant difference in the mean length of clinical crown length at rest between male and female samples. In their research, the measurements were $1.91 \mathrm{~mm}$ for males and $3.40 \mathrm{~mm}$ for females, respectively; reported the visible amount of maxillary central incisor to be $1.82 \pm 2.80 \mathrm{~mm}$ for white males and $4.09 \pm 2.27$ $\mathrm{mm}$ for white females. For the black subjects, such amounts were $1.52 \pm 1.70 \mathrm{~mm}$ and $2.61 \pm 1.51$ $\mathrm{mm}$, respectively. In comparison to Al Wazzan (2004), the mean visible amount of maxillary central incisors in males was $2.66 \pm 1.50 \mathrm{~mm}$ and in females was $2.91 \pm 1.89 \mathrm{~mm}$.

The variations may to some extent be explained by differences in measuring techniques and ethnic differences between the populations studied. It was found in the present study females exposed more of the maxillary central incisor than males; consistent to other studies ${ }^{19,20}$ (Connor and Moshiri, 1985; Vig and Brundo, 1978), which showed statistically significant in their results. Connor and Moshiri (1985) reported a significant difference between the white females and black females; however; the male subjects were nearly the same. Study showed the visible amounts of teeth when the lips are at rest increase from African blacks to Arabs and Asians for the maxillary anterior teeth. With the increasing age, the amount of maxillary central incisor exposed when the lips are at rest decreased from 3.13 $\mathrm{mm}$ at age 20 to $0.93 \mathrm{~mm}$ at age 60 . With this, it is clear that as time and gravity wins out; the tissues surrounding the mouth sag. The visible length of maxillary anterior teeth diminishes and the amount of mandibular anterior teeth that is visible increases. A similar finding. ${ }^{9}$

Facial muscle exercises might help in preventing muscle sagging. The present study showed no statistically significant gender differences in maxillary central incisor display during smiling, although females displayed more of the clinical crown length of maxillary central incisor than males. The mean clinical crown length of maxillary central incisors during smiling of Malaysian Malay males and females studying in Universitas Padjadjaran are $8.17 \pm 2.25 \mathrm{~mm}$ and $9.07 \pm 2.13 \mathrm{~mm}$ respectively. These results were in agreement with a previous study done by AlHabahbeh, with mean values for both males and females; $8.72 \pm 1.27 \mathrm{~mm}$ and $9.14 \pm 1.45 \mathrm{~mm}$. Some studies. ${ }^{13,14}$

that investigated anterior or tooth visibility have revealed significant differences in smile type between males and females, with females presenting most frequently with a high or average lip line, thus displaying greater amounts of tooth crown length. In addition, during maximum smiling, it was shown that females displayed an average of $87 \%$ of the clinical crown length of maxillary anterior teeth compared to an average of $78 \%$ for males. However, the opposite was true for the mandibular anterior teeth. Kapagiannidis reported that the mean amount of tooth display for maxillary central incisors was $78 \%$ in males, and $87 \%$ in females, respectively.

As studied by Tjan and colleagues (1984) in dental and hygiene students, three smile line classifications exist, based on the location of the upper lip relative to the upper anterior teeth. The analysis appraised only patients up to age 30 . With time, the lips become less everted and less elastic. In other words, the lip line changes. Older patients show less of the maxillary teeth and 
more of the mandibular. Fifteen-year-old subjects reveal $10 \mathrm{~mm}$ of maxillary central incisal length during smiling and $5 \mathrm{~mm}$ at rest. ${ }^{13}$ confirmed agecorrelated changes and discovered that women tended to exhibit twice as much maxillary incisor length compared to men. Notice that with time, the total level of tooth exposure at rest drops from $5 \mathrm{~mm}$ at age 15 years to $3 \mathrm{~mm}$ at age 40 .

Gingival display during smiling presented no significant differences between gender groups in the maxillary central incisor. The mean gingival displays shown by males and females during smiling are $0.79 \pm 0.27 \mathrm{~mm}$ and $1.25 \pm 1.15 \mathrm{~mm}$. Females displaying more gingival during smiling compared with males in maxillary central incisor area, respectively.

The present study reported that during posed smile the percentage of females who showed gingival during smiling is higher compared to males with $50 \%$ for females and $24 \%$ for males. Out of 40 female subjects, 20 of them showed gingival when smiling while for males only 6 people out of 25 showed their gingival during smiling. A considerable gender difference associated with the frequency of a high smile line (approximately a 2 to 1 ration for females over males) has been reported in previous studies. 7,13

This predominance of high smile lines for females is supported by the findings in the present study as well. Out of these 26 people who showed gingival during smiling, 3 of them recorded more than $3 \mathrm{~mm}$ gingival display and all of them are females with the mean value $3.51 \mathrm{~mm}$. There are 17 females and 6 males who have the level of gingival display between 0 till $3 \mathrm{~mm}$ during smiling. The mean values of the people showing gingival in this level are $0.78 \mathrm{~mm}$ for males and $0.85 \mathrm{~mm}$ for females. While the rest, 20 females and 19 males showed no gingival at all during smiling. In a study of 425 students Crispin and Watso reported that the gingival margin was visible in $66 \%$ of the participants in natural smile. examined 454 young adults and classified them into 3 categories according to the position of the smile line. The study used the following classification: 1) the smile line is above the cement-enamel junctions, the gummy's reveals interproximal gingival; and 3) the smile line reveals less than $75 \%$ of the anterior maxillary teeth. Class 1 accounted for $10.6 \%$; Class 2 accounted for $68.9 \%$ and Class 3 accounted for $20.5 \%$. Tjan et al (1984) reported that $79.5 \%$ of patients presented periodontium visibility without specifying the type of smile. Jensen et al (1999) reported that about $70 \%$ of patients revealed more than $25 \%$ of their periodontium in their usual contact smile. We cannot compare this data because we cannot know from their classification how many participants did not reveal their periodontium at all.

This important finding reveals the necessity for increased esthetic awareness in restoring maxillary incisors and especially the placement and waxing of their associated gingival in removable prostheses However, more then 55\% of subjects that participated in the present study did not display gingival associated with the anterior region during posed smiling. Accordingly, the routine sub-gingival placement of esthetic crowns could be an unnecessary over-treatment that might compromise periodontal health. ${ }^{21}$ For complete denture patients, a guideline was suggested to adjust the vertical length of the maxillary occlusion rim in the anterior region by extending it approximately $2 \mathrm{~mm}$ below the relaxed lip to establish the lip length incisal edge relationship and accordingly a visible amount of the maxillary central incisors teeth. ${ }^{22}$

However, female patients may reasonably be expected to show 4 to $5 \mathrm{~mm}$ of tooth beneath the resting lip, especially if the patient had a class II division 1 profile or short upper lip. ${ }^{23}$ Also, the visible amount of anterior teeth can be one of the helpful guidelines for determining the appropriate vertical dimension of occlusion. ${ }^{23}$

It has been shown that the maxillary central incisor is a superior reference to the rest of the anterior teeth in regard to the amount of visible tooth surface. In addition, maxillary central incisors are the most dominant anterior teeth in the dental arch because they can be seen in their full size. ${ }^{24}$ The maxillary right central incisor was therefore used as a parameter to assess racial and gender differences. ${ }^{25}$ Accordingly, some variations were obvious concerning tooth and gingival display of the contralateral side that were not recorded in the present study, as only the right side display was measured. Esthetic considerations could become a major concern for patients seeking prosthodontic services in the future. ${ }^{26}$ Traditionally, prosthodontist have been taught 
to evaluate facial esthetics to restore overall harmony to the face. ${ }^{27}$ Clinicians are encouraged to create or restore a pleasant facial appearance by developing a balanced and pleasant smile. ${ }^{28}$ Prosthodontist, and many patients alike, often focus on key frontal esthetic parameters, and certain esthetic canons establish a relationship between eyes and teeth. ${ }^{29}$

Gender differences regarding the clinical crown length display of maxillary central incisors and associated gingival at rest and in posed smile positions should be considered on an individual basis when restoring teeth, as the results of the present study demonstrate many variations between males and females, particularly in a rest position. However, the esthetic appearance of maxillary incisors display during smiling may be generalized over both genders as no statistically significant gender differences were recorded.

\section{CONCLUSION}

The conclusions of this research are females displayed more clinical crown length of maxillary central incisors than male at rest, during smiling, no gender differences in maxillary central incisors display were recorded and females displayed more maxillary gingival than males during smiling.

\section{REFERENCE}

1. Rufenacht CR. Fundamentals of Aesthetics. London: Quintessence Publishing: 18. 1990

2. Qualtrough AJ, Burke FJ. A look at dental esthetics. Quintessence Int. 25:7-14. 1994

3. Sheets CG. Modern dentistry and the esthetically aware patient. J. Am. Dent. Assoc. special issue.1987. 103-105 pp.

4. Levin JB. Esthetic diagnosis, In Current Opinion in Cosmetic Dentistry. Golub Evan J, Philadelphia, Current Science: 9-17. 1995.

5. Thompson L, Malmberg J, Goodell, N, Boring R. The distribution of attention acrossDiscourse Processesatalker's.38:145-168. 2004 face.

6. Garber DA, Salama MA. The aesthetic smile: diagnosis and treatment. Periodon 2000. 1996;11:18-28.

7. Ackerman $M B$, Ackerman J. Smile analysis and design in the digital era. J. Clin. Orthod. 2002;36(5):221-36.
8. Van der Geld P, Oosterveld P, KuijpersJagtman, A.M. Age related changes of the dental aesthetic zone at rest and during spontaneous smiling and speech. European $J$ Ort. 2008;30(1):366-373.

9. Tjan AHL, Miller GD, The JGP. Some esthetic factors in a smile. J. Prosthent. Dent. 1984;51(1):24-28.

10. Landa LS. Practical guidelines for complete denture esthetics. Dent. Clin. North. Am. 1977;21(2):285-298.

11. Behrend DA. An improved esthetic control system. Int. J. Pros. 1988;1(2):80-86.

12. Al-Wazzan KA. The visible portion of anterior teeth in rest position. $J$ Contemporary Dent Practice. 2004;5(2):1-7.

13. Peck $S$, Peck $L$, Kataja $M$. The gingival smile line. Angle Orthod. 1992;62(2):91-100.

14. Owens EG, Goodacre CJ, Loh PL. A multicenter interracial study of facial appearance. Part 2: A comparison of intraoral parameters. Int. J. Pros. 2002;15(3):283-8.

15. Kapagiannidis D, Kontonasaki E, Bikos P, Koidis, $P$. Teeth and gingival display in the premolar area during smiling in relation to gender and age. J. Oral Rehabil. 2005;32(1):830-837.

16. Oguz $O$. The proportion of the face in younger adults using the thumb rule of Leonardo da vinci. Surgical and Radiologic Anatomy; 1966;18:2.

17. Sabri R. The eight components of a balanced smile. JCO, Inc volume XXXIX. 2005;3:155167.

18. Jensen J, Joss A, Lang NP. The smile line of different ethnic groups in relation to age and gender. Acta Med Dent. 1999;4:38-46

19. Connor AM, Moshiri F. Orthognathic surgery norms for American black patients. Am. J. Orthod. 1985;87(2):119-34.

20. Vig RG, Brundo GC. Kinetics of anterior tooth display. J Pros Dent. 1978;39(5):502-4.

21. Ahmad I. Anterior dental aesthetics: dentofacial perspective. Br. Dent. J. 2005;199:81-88.

22. Zarp GA, Bolender CL, Carlsson GE. Boucher's prosthodont for edentulous patients. $11^{\text {th }} \mathrm{ed}$. St. Louis, Missouri: Mosby. 1997. p. 191. 224.

23. McCord JF, Grant AA. Prosthetic Dentistry. British Dent J. 2000. p.71-74.

24. Hasanreisoglu U, Berksun S, Aras K, Arslan I. An analysis of maxillary anterior teeth: 
facial and dental proportions. J Pros Dent. 2005;94:530-538.

25. Ballard ML. Asymmetry in tooth size, a factor in etiology, diagnosis and treatment of malocclusion. Angle Orthodontist. 1944;14(2):67-71.

26. Albino JE, Tedesco LA, Conny DJ. Patient perceptions of dental-facial esthetic: shared concerns in orthodontics and prosthodontics.
J Pros Dent. 1984;52(1):9-13.

27. Di Biase DD. Class II malocclusion: making the face fit. Dent. Update. 1991;6(2):429-35.

28. Matthews TG. The anatomy of a smile. J. Prosthet. Dent. 1978;39(2):128-134.

29. Farrow AL, Zarinna K, Azizi K. Bimaxillary protrusion in black Americans- an esthetic evaluation and treatment considerations. Am. J Ort Dent Orthop. 1993;104(3):240-250. 